\title{
NOTA ADICIONAL SOBRE CERVANTES Y EL SILENCIO
}

Ha llegado a nuestras manos un libro de José Bergamín, La corteza de la letra (Buenos Aires, 1957), que contiene, en el capítulo intitulado "Los maravillosos silencios" (pp. 38-42), una serie de apostillas relacionadas con el tema de nuestro artículo "El silencio en el Quijote", NRFH, I 2 (1958), 160-180. Señala Bergamín tres "maravillosos silencios": el del entierro de Grisóstomo, el de la casa de don Diego de Miranda y el del episodio de Ruperta en el Persiles, donde Cervantes describe a ésta acechando, "sepultada en maravilloso silencio", en la estancia de Croriano, a quien piensa dar muerte ${ }^{1}$. En ellos encuentra Bergamín una "resonancia espiritual coincidente y significativa", cuya clave, si bien le entendemos, es un tema común de amor y muerte juveniles. En la casa de don Diego el tema se halla expresado en las glosas del joven don Lorenzo y en su soneto sobre Píramo y Tisbe ("Habla el silencio allí, porque no osa / la voz entrar por tan estrecho estrecho; / las almas sí...", t. 3, p. 235); el soneto entusiasma mucho a don Quijote, como observa Bergamín. Además, "la sosegada casa [es] apaciguadora de las andantes inquietudes caballerescas de don Quijote, con su «maravillosa quietud» de amor, de poesía". Como se ve, el ángulo desde donde mira el crítico al hacer estas interesantes observaciones, difiere un poco del nuestro. Por otra parte, el comentario de Bergamín nos ha hecho consultar el Con permiso de los cervantistas de Azorín, donde hallamos, además de un capítulo - "La casa de Miranda"- que toca de soslayo nuestro tema, otro - "Cervantes y la soledad"- donde la conjunción cervantina de "maravilla" y "silencio" se explica finamente por su "ansia de soledad"'.

Tan sugestivos comentarios nos han hecho volver sobre La Galatea a fin de ver si en esa obra primeriza se anticipa en algo el papel estilístico que desempeña el silencio en el Quijote. Lo que se nota primero es que no faltan antecedentes de los "maravillosos silencios" del Quijote. "Vn sossegado y marauilloso silencio" sobrecoge a los pastores que esperan la presentación de unas églogas en cierta boda rústica (t. I, p. 199); "vn marauilloso silencio" guardan los pastores al encaminarse al Valle de los Cipreses donde ha de celebrarse el aniversario de las exequias del "nombrado Mileso" (t. 2, p. 187); otro "marauilloso y sossegado silencio" hay ante el sepulcro del mismo (t. 2, p. 195). Pero es de notar que sólo son "maravillosos" en $\mathrm{La}$ Galatea estos tres silencios que realzan la solemnidad de una ceremoniosa ocasión (boda, funerales). Si se exceptúa el "maravilloso silencio" del entierro de Grisóstomo, que pertenece también a un mundo pastoril, se verá que estos "mara-

(Durán, 305; W., 17o) recogidas por Baruh Uzifl ("Shte romansot", Yeda-Am, 2, 1954, p. 261) y Atrias (núm. 25): "El que traía las cartas / cien y veinte años tenía, // no vos topéis maravilla, / que padre y madre tenía". El pliego del British Museum, publicado por López Estrađa, ofrece el texto siguiente: "El moro que las [cartas] llevava / ciento y veinte años avía, / ciento y veinte años el moro, / y padre y madre tenía".

${ }^{ \pm}$Ed. Schevill-Bonilla, t. 2, p. 165. A esta edición remitimos para todas las citas de obras de Cervantes.

${ }^{2}$ Azorín, Obras completas, Madrid, 1954, t. 9, pp. 369-97 I y $3^{82-3^{8}}$. 
villosos silencios" se distinguen netamente de los del Quijote, los cuales se producen como por milagro, en medio del trajín y el bullicio de la cotidiana vida humana. ¿Qué ruidos hay en un escenario pastoril, fuera de los muy previsibles del "manso viento", de los "pintados pajarillos", de los "lastimosos suspiros" y los acordes de "rústicos rabeles"? Por su misma calidad de absoluto, el silencio es connatural con ese mundo depurado y unidimensional. ("Puesto silencio a todo, sin ser menester pedírselo", escribe Cervantes en una ocasión: t. 1, p. 177.) Sólo se destaca y se torna "maravilloso" el silencio cuando se intensifica para un efecto solemne. Falta la dinámica dialéctica silencio-ruido, tan significativa en el Quijote. Por el contrario, estamos en un mundo de vidas estáticas, donde asoma el silencio por los intersticios de todas las conversaciones: "Calló en diziendo esto el famoso Damón, y lleuó tras la suya las contrarias opiniones" (t. 1, p. 229); "Calló Arsindo y esperó la respuesta de los pastores" (t. 1, p. 231); "Calló diziendo esto la hermosa dama, y estuuo vn poco esperando a ver lo que Grisaldo respondía" (t. 2, p. 11). No puede trabarse, con un tempo tan lento, el diálogo en que, como escribe Gilman a propósito de la Celestina, "se encuentran dos vidas"; la soledad no es ya, como en el Quijote, añoranza, sino presencia permanente. En ella se reintegran los personajes al silencio: "buscando algún solitario lugar adonde en el silencio de la noche pudiesse soltar la rienda a sus amorosas imaginaciones..." (t. 1, p. 15); "combidándole la soledad y silencio de vn pequeño pradezillo que junto a las paredes de la aldea estaua..." (t. 1, p. 173). Frente a la casi ausencia en el Quijote de los silencios del mundo ambiente, o su destrucción por ruidos grotescos (los batanes, los animales del Toboso), los hallamos intactos en La Galatea: "El sossegado silencio se estendió por todo aquel sagrado valle..." (t. 2, p. 2o6).

En cambio, no cabe hablar de silencios que caractericen a unos personajes faltos de individualidad; en este sentido hallamos en La Galatea, cuando más, sólo unos estados de ánimo aislados en cuya representación entra a veces un factor de silencio. Pero entonces no se trata sino de convenciones del género pastoril y cortesano - el silencio atormentado del rendido amante; el callar discreto del ya correspondido. Es aquí, en lo tocante a los personajes, donde más notablemente enriquecerá Cervantes, en el Quijote, la función expresiva del silencio. Con todo, vemos en algún momento excepcional un anticipo de aquel silencio preñado de un personaje que escucha, elemento constitutivo del diálogo del Quijote, reflejo de vidas ya no estáticas sino que se desviven hacia un porvenir: "Hasta este punto hauía estado callando Erastro..., pero... rompió el silencio" (t. 1, p. 107); "En todo el tiempo que con Nísida y su hermana estuue hablando, jamás la menor hermana habló palabra, sino que, con vn estraño silencio, estuuo siempre colgada de las mías" (t. 1, p. 145).

En resumen, sólo por excepción el silencio tiene en La Galatea un papel estilístico netamente cervantino. Más a menudo es un elemento de estilización genérica, que creemos tendría equivalentes en otras novelas pastoriles. Engloba y asordina este mundo, alejándolo de la realidad, lo mismo que hacen el ucronismo y el utopismo. Si la frecuencia de 
los silencios - hemos señalado todos- denuncia ya una especial sensibilidad acústica, sólo al contacto de otra idea creadora más poderosa se potencializará aquélla hasta volverse elemento plenamente expresivo del estilo cervantino.

Quien ahonde en el estudio del silencio en la literatura verá que cabe hacer, tratándose de los personajes, una distinción -no siempre neta- entre un silencio humano positivamente expresivo o elocuente, alusivo a lo que no puede expresar el lenguaje, y otro negativo, es decir, un callar algo, por prudencia, por doblez, por modestia, por renuncia, por timidez, etc. Nos hemos acordado de tal distinción al volver sobre el episodio del Persiles de que habla Bergamín, donde encontramos citados "aquellos antiguos versos castellanos que dizen "Las cosas de admiración / no las digas ni las cuentes: / que no saben todas gentes / cómo son»" (t. 2, p. 154). Ya hemos hecho notar en el estudio citado cómo el silencio es muchas veces efecto positivo de la admiración, pero el silencio admirativo puede también cargarse de escepticismo o desconfianza; entonces un silencio negativo de renuncia o prudencia lo anticipa y evita, y se esfuma el diálogo. Prudencia de todas las épocas, sin duda, pero tal vez muy particularmente de la época post-tridentina en que escribia Cervantes. "Para saber callar en romance y hablar en latín, discreción es menester, amigo Berganza", leemos en el Coloquio de los perros ${ }^{3}$. Por los mismos años escribe Espinel: "Yo reventaba por hablar, pero consideraba que me ponía a peligro de no ser creído. Más vale callar que dar ocasión de incredulidad o murmuración. La admiración da ocasión al silencio, y desta vez quise ver si podía enseñarme a callar"

Silencio positivo, silencio negativo: en fin de cuentas, uno y otro brotan de la vida. Apuntemos, para terminar, el caso tal vez más "sensacional" de un silencio de admiración que nos ofrece la vida de los Siglos de Oro. Mucho se ha observado que a menudo, en la experiencia de los españoles, la realidad del Nuevo Mundo sobrepasaba las más inverosímiles ficciones. Al dar cuenta Cabeza de Vaca, en sus escuetos Naufragios, del efecto que produjo él sobre cuatro españoles que lo vieron surgir de repente del corazón del continente norteamericano, donde era imposible que hubiera blancos, escribe: "Estuviéronme mirando mucho espacio de tiempo, tan atónitos que ni me hablaban ni acertaban a preguntarme nada". Se dirían salidas de la pluma de Cervantes esas palabras. Plantadas en la vida, confirman cuánto acertaba su genio al pintar las reacciones humanas en las insólitas circunstancias que él inventaba.

Alan S. Trueblood

Brown University.

${ }^{3}$ La frase del Coloquio (t. 3, p. 182) la recoge Claudro Gullé̂n en "Estilística del silencio. (En torno a un poema de Antonio Machado)", $R H M, 23$ (1957), p. 285 y nota 59. Cf. nuestro estudio citado, pp. $177^{-1} 78$. El "sentido problemático del idioma (o conciencia del silencio)" que observa Guillén en el Coloquio, habrá que extenderlo a otras obras de Cervantes, principalmente el Quijote. Tal sentido constituye, para el autor de ese sugestivo estudio, un caso excepcional entre los autores clásicos.

${ }^{1}$ Marcos de Obregón, ed. S. Gili Gaya en Clás. cast., Madrid, 1922, p. 185. 